\title{
A Behavioral Economics Study on the Management Accountant's Professional Networking Practices through Mobile Technologies
}

\author{
Ashish Varma*, Subhransu Sahoo \\ Institute of Management Technology, Ghaziabad, India \\ Email:*avarma@imt.edu
}

How to cite this paper: Varma, A. and Sahoo, S. (2018) A Behavioral Economics Study on the Management Accountant's Professional Networking Practices through Mobile Technologies. Theoretical Economics Letters, 8, 3092-3108.

https://doi.org/10.4236/tel.2018.814192

Received: September 10, 2018

Accepted: October 22, 2018

Published: October 25, 2018

Copyright $\odot 2018$ by author and Scientific Research Publishing Inc. This work is licensed under the Creative Commons Attribution International License (CC BY 4.0).

http://creativecommons.org/licenses/by/4.0/

(c) (i) Open Access

\begin{abstract}
The objective of this study was to ascertain the management accountant's (MA) usage of smartphone for professional networking purposes. The study was conducted during mid-2017 to mid-2018 using a partial least squares-structural equation modeling (PLS-SEM) technique. The study included a sample of 168 management accountants from India. The study found out that the enjoyment of professional networking activity (EPA) has a direct significant effect on the perceived value of smartphone professional networking service (PVSP) and that the perceived risk (PR) had a significant negative effect on the trust in advice acquired from a smartphone professional networking service (TCASP). As expected, privacy concerns (PC) had a significant direct effect on the perceived risks (PR). The PVSP had a direct positive effect on TCASP. Finally, it was observed that PR mediates the relationship between PC and TCASP. Thus, this study contributes by bringing new empirical insights on the actual usage of mobile technology for professional networking purposes in an emerging market context and has significant ramifications for providers of such services.
\end{abstract}

\section{Keywords}

Behavioral Economics, Management Accountant, Professional Networking, Mobile Technology, PLS-SEM

\section{Introduction}

Professional networking service (PNS) is a specific networking service that is aimed at creating and maintaining business and professional relationships to fa- 
cilitate business and career growth. PNS is also beneficial for sharing business and professional opportunities. For instance, LinkedIn is one of the most well-known professional networking services, which is internationally popular amongst the professionals and business persons. For Management Accountants (MA), there is a need to remain connected with other professionals to update their information, to share opportunities and to update their skills. This study investigates the smartphone based professional networking choices of MAs through a behavioral economics lens. The positives of professional networking through smartphones were assessed against the negatives and then were interpreted in this study.

The important question was, why is the use of behavioral economics perspective is essential for this study? As per Guzavicius et al. [1] behavioral economics discusses the effect of social, cognitive and emotional factors on the economic decision of individuals and the consequences of such decisions. Behavioral economics is quite contrarian in the sense that it neither presumes a fixed personality of the decision maker nor does it presume equilibrium in processes. It presumes the interplay between diverse actors and the reality and assumes that the actors are learning organisations themselves. Thus, behavioral economics blends economics with other disciplines such as psychology, philosophy, ethics, sociology etc. It is due to such integration that behavioral economics is better suited to explain both the individual behavior and the anomalies associated with such behavior. This "behavioral economics underpinning" was very relevant and necessary for the present study of the management accountants since there were no prior assumptions made regarding their behavior and there were no best practices available to benchmark against either.

Individuals have more or less the same information which they interpret and use differently for decision making purposes by applying simple rules and processes [2]. This is in synchronisation with the "bounded rationality" model which assumes that agents possess a limited ability to analyse the information. To this extent behavioral economics also suspends the "rational man" assumption of traditional economics. In the context of smartphones and professional networking, the upside was the ease of use and the presence of virtually limitless possibilities of untapped opportunities. These were weighted against the privacy concerns and the perceived risks that were associated with sharing personal information on the internet. Since the MAs also held key decision-making positions in their organisations, they needed to be extra cautious regarding such choices. Some firms explicitly had issued guidelines to all their employees regarding the information sharing on the public platforms/networking sites in the cyberspace which were applicable to MAs.

The use of mobile technology in education and learning has been probed by Ponce et al. [3]. Mobile learning has a great promise of improving the learning quality. Boruff and Storie [4] stated that the key benefits of mobile learning were the convenience of getting timely information, accessibility, compact size of the mobile phone, portability and speed of information access. Apart from these, the 
other factors were efficient use of time and flexibility in operations. However, there was little literature on the use of mobile technology for networking among professionals in the emerging market context. This study is an attempt to bring fresh empirical insights in this domain.

The study found out that the enjoyment of professional networking activity (EPA) has a direct significant effect on the perceived value of smartphone professional networking service (PVSP) and that the perceived risk (PR) had a significant negative effect on the trust in advice acquired from a smartphone professional networking service (TCASP). Privacy concerns (PC) had a significant direct effect on the perceived risks (PR). The PVSP had a direct positive effect on TCASP. Finally, it was observed that PR mediates the relationship between PC and TCASP.

The study makes three distinct contributions. First, it contributes through a rigorous empirically tested model, the smartphone usage choices for professional networking. Second, it uses the behavioral economics theory as an overarching theory, to study the professional networking choices of MAs. Finally, as a methodological contribution it demonstrates the application of Importance Performance Analysis (IPMA) and Multi Group Analysis (MGA) techniques in an emerging market context.

\section{Conceptual Development and Hypothesis Testing}

Technology has improved the quality of human life. With a smartphone, there is no limitation of space and time for any professional who has multiple commitments. Previous studies have found that the smartphone advantage can apply in diverse domains and bring up niche value to users [5]. The present study aimed to empirically investigate the usage of mobile technology by MA's for professional networking purposes. Due to the app stores, the smartphone user can download different apps and get benefited from the services [6] which is quite beneficial for professional networking.

However, some other scholars such as Okazaki et al. [7] argued that high privacy concern blocks the consumers' attitude towards maximisation of technology adoption on the other hand some other scholars opine that smartphones have constraints, in comparison to personal computer, such as a small screen [8]. Notwithstanding any of the above the smartphone is very portable, convenient and easy to use without limitations of time and space for MAs.

Professional networking leads to opportunity discovery which involves action by certain individuals who take initiative on neglected opportunities [9]. The MAs are engaged in the organisational decision-making process and provide inputs for planning, control and performance evaluation purposes. Thus, for MAs, professional networking can have benefits at both organizational level and at individual level. Scholars have been intrigued by the fact that some individuals are able to discover business ideas more than others. This may be the result of perspective development which happens by having a large network. Thus, inter- 
esting question in this context is the role of technology, such as mobile technology, in facilitating the opportunity discovery process by practicing MAs. Tie generation theories posit that a tie is formed as a result of the personal preferences [10] and smartphones can help initiate and maintain the tie generation process.

This study builds on the study of Chang and Liu [5] who stated that the enjoyment of networking activity and the perceived value of smartphone networking service would positively affect the user's trust in advice from smartphone networking service. They further add that privacy concern and perceived risk would negatively affect such trust in advice from smartphone networking services. This was in agreement with Venkatesh et al. [11] who suggested that perceived enjoyment associates with perceived value in a pleasure oriented environment. Overall, the current research on the professional networking through mobile technology was at best, partial and scattered especially in the emerging market context.

Network orientation is the extent to which a person is willing to depend on social networks in his daily socialization. It has also been found that in a given network the quality of connections changes over time [12] and hence a need to constantly refresh the ties at regular intervals and a smartphone can be very useful for this purpose. As per Casciaro et al. [13] people appreciate others who understand their values and identities. Smartphones help bridge the gap between fellow professionals such as MAs, who just like practicing managers, also require to meander through strict organisational controls by enhancing their risk-taking abilities [14] in order to create a competitive advantage for their firms.

Prior works by scholars such as Pitt et al. [8] have increased our appreciation of smartphones applications (apps) which help the user to gain important information. However, online social services require the user to share their personal information such as name, pictures etc. [15] which makes many professionals uncomfortable. As per Chang and Liu [5] this process leads to trust concerns and privacy concerns. In this context, trust connotes an individual's beliefs of other individual's ethical behavior [16]. Trust can also be understood as a user's belief in the safety, reliability, strength and competence of a system the user is working on.

Kane et al. [17] suggested that social networking systems provide the users with better scope and influence and Cheng and Ho [18] opined that people are influenced by their friends to join a social networking system. This suggests that professional perceive value in professional networking. Teas and Agarwal [19] stated that perceived value was the net effect of the benefits the customers receive and the sacrifices the customers made in the process of receiving the benefits. As per Sheth et al. [20] there are five dimensions of perceived value which are social value, emotional value, functional value, epistemic value and conditional value. Venkatesh et al. [11] suggest that perceived enjoyment associates with perceived value in a pleasure-oriented environment. To be widely accepted, 
professional networking via a smartphone needs to be a pleasurable experience for MAs.

Privacy concern, as per Nofer et al. [21] capture the user's opinion about the collection and maintenance of personal information. These privacy concerns in turn effect the actual smartphone usage behavior of the professionals. Lankton and McKnight [22] stated that privacy concern in the smartphone networking services is related to the protection of user's personal information, avoiding unauthorised access and avoiding data losses. These are key priorities for most professionals. Dowling and Staelin [23] stated that perceived risk is the user's perception of uncertainty about the final outcome of an activity or a behavior. The above discussion leads us to the following hypothesis:

H1: Enjoyment of professional networking service activity (EPA) has a direct positive effect on perceived value of smartphone professional networking service (PVSP).

H2: Perceived risk (PR) has a negative direct effect on Trust in advice acquired from smartphone professional networking service (TCASP).

H3: Privacy concern (PC) has a negative direct effect on enjoyment of professional networking service activity (EPA).

H4: Privacy concern (PC) has a positive direct effect on perceived risk (PR).

H5: Perceived value of smartphone professional networking service (PVSP) has a positive direct effect on Trust in advice acquired from smartphone professional networking service (TCASP).

H6: Perceived risk (PR) mediates the linkage between Privacy concern (PC) and Trust in advice acquired from smartphone professional networking service (TCASP).

\section{Methods}

The methods used for the study were chosen from those which best suit the research agenda. The study was thus positivist in nature, and used a quantitative survey method. The data collection method was tailored to suit the exact research question of the study.

\subsection{Research Design}

The data from MAs was collected during national and international conferences, seminars and other professional networking events such as study group meetings held in various cities of India and which were attended by professional MAs. To initiate the process, a prior request for permission was made to the conference chair. A formal communication in this regard was send along with a copy of the questionnaire for their perusal at least one week before the event. A small time slot of 15 minutes was requested. On the day of the event, the hard copy of the questionnaire was given at the time of registration itself and collected subsequently from the participants. All the data collected was anonymous and no names were asked. However, information regarding their professional quali- 
fication, gender, experience and age was asked since the study had a behavioral economics underpinning. The target audience was MAs engaged in the decision-making process in their respective firms. All the information was collected during mid-2017 to mid-2018. A pretested [24] and pilot study validated [25] questionnaire with a 7-point MA self-rating Likert scale was administered to 400 management accountants. A total number of 194 responses were obtained out of which 168 final set of questionnaires were taken which were complete in all respects. This gave a response rate of $42 \%$.

For the purpose of the study, MAs were defined as those professionals who were designated by their respective organisations and were primarily responsible for either one or more sub-domains, such as cost and financial accounting, management audit, legal, taxation, or compliance work. A minimum work experience of three years was a prerequisite to be considered for the study. The face validity of the questionnaire was established by taking the inputs of two academicians and three industry experts. Among the respondents $22.02 \%$ were female (Table 1).

The procedure as advocated by Podsakoff [26] for controlling for common method variance was strictly adhered to, during the study. The MAs were assured that the data collected would be used for academic research only and they were assured of complete anonymity. They were also told that there is no single correct answer and that their responses would not be shared with their seniors and peers.

Partial least squares structural equation modelling (PLS-SEM) is useful technique which requires minimum restrictions on measure scales and which is used to model latent constructs under conditions of non-normality as well [27]. For data analysis PLS-SEM was used since it also simultaneously measures the structural model and the measurement model [28]. PLS-SEM also does not suffer from identification challenges due to small sample size. The Smart PLS package version 3.2.7 was used for the data analysis [29].

\subsection{Measurement Variables}

The scales for the constructs were taken from previous reputed studies. The four-item scale for privacy concern was taken from Shin [30] and Tan \& Qin [31]. The three-item scale for perceived risk was taken from McKnight et al. [32]. The three-item scale for enjoyment of professional networking activity

Table 1. Description of sample, $\mathrm{n}=168$.

\begin{tabular}{ccc}
\hline Variable & Values & $\%$ \\
\hline \multirow{2}{*}{ Age } & $25-35$ & $26.19 \%$ \\
& 36 and above & $73.81 \%$ \\
Gender & Male & $77.98 \%$ \\
& Female & $22.02 \%$ \\
Industry category & Manufacturing, assembly, construction & $41.66 \%$ \\
& Trading, services, operations, logistics, & $58.34 \%$ \\
\hline
\end{tabular}


(EPA) was taken from Moon and Kim [33]. The five-item scale for Perceived value of smartphone professional networking service (PVSP) was taken from Teas and Agarwal [19] and Zeithaml [34]. Finally, the five-item scale for trust in advice from smartphone professional networking was taken from Hsu et al. [35] and Gefen [36]. After taking these scales, the validity and the reliability of these scales was established.

\section{Results}

The study followed a two-step approach [37] to analyse and interpret the PLS SEM results by the assessment of the measurement model and the assessment of the structural model. The tables have been prepared by the author by taking the relevant output from the software Smart PLS [29]. The figures presented in the paper are derived directly from the software [29].

\subsection{Evaluation of Measurement Model}

All the constructs were measured reflectively (Table 2). The composite reliability $(\mathrm{CR})$ which measured the internal consistency of the constructs was more than the 0.7 threshold for all the constructs. The Cronbach's alpha [38] was greater than 0.7 for all the constructs excepts PR which had a value of 0.628 which was close to 0.7 and therefore, retained. The outer loading, which measure the indicator reliability were greater than 0.7 and significant at $95 \%$ level except PR3 and PVSP 5 which were both retained due to their conceptual and theoretical significance. Average variance extracted (AVE) was calculated for all the reflective constructs to ascertain the convergent validity of the constructs and it was greater than 0.5 and significant at $95 \%$ level. For ascertaining the discriminant validity, HTMT ratio [39] (Table 3) was calculated and was found to be below 0.85 for all the items in the constructs. With a good model measurement, the model was fit for a structural assessment.

\subsection{Evaluation of Structural Model}

Post ascertaining that the constructs were both reliable and valid and thus could be used for the structural model assessment [40] another calculation was carried out to rule out collinearity. For this purpose, outer variance inflation factor (VIF) values were calculated (Table 4). VIF is the reciprocal value of tolerance [41] the values were found to be less than 5 and thus there was no collinearity in the data.

The path coefficients shown in Figure 1 reflect the estimation of change in the endogenous construct for a single unit of change in the predictor construct. The PLS algorithm is based on a non-parametric bootstrap procedure (here 168 cases, 5000 samples, no sign change option) in order to ascertain the significance of the coefficients and also to discover the mediating effects as per Preacher and Hayes [40]. Thus, a bootstrapping procedure was undertaken to check the significance of the effects which are mentioned in Table 6, Preacher and Hayes [40] 
Table 2. Reliability and validity.

\begin{tabular}{|c|c|c|c|c|c|}
\hline Construct & Items & Factor Loadings & $\mathrm{CR}$ & Cronbach Alpha & AVE \\
\hline \multirow[t]{4}{*}{ Enjoyment of PNS activity } & & & 0.862 & 0.763 & 0.676 \\
\hline & EPA1 & 0.751 & & & \\
\hline & EPA2 & 0.839 & & & \\
\hline & EPA3 & 0.871 & & & \\
\hline \multirow[t]{5}{*}{ Privacy Concern } & & & 0.909 & 0.868 & 0.715 \\
\hline & PC1 & 0.859 & & & \\
\hline & PC2 & 0.846 & & & \\
\hline & PC3 & 0.884 & & & \\
\hline & PC4 & 0.789 & & & \\
\hline \multirow[t]{4}{*}{ Perceived Risk } & & & 0.788 & 0.628 & 0.559 \\
\hline & PR1 & 0.833 & & & \\
\hline & PR2 & 0.799 & & & \\
\hline & PR3 & 0.586 & & & \\
\hline \multirow[t]{6}{*}{$\begin{array}{l}\text { Perceived value of } \\
\text { smartphone PNS }\end{array}$} & & & 0.899 & 0.860 & 0.642 \\
\hline & PVSP1 & 0.807 & & & \\
\hline & PVSP2 & 0.886 & & & \\
\hline & PVSP3 & 0.854 & & & \\
\hline & PVSP4 & 0.751 & & & \\
\hline & PVSP5 & 0.692 & & & \\
\hline \multirow[t]{6}{*}{$\begin{array}{l}\text { Trust in advice acquired from } \\
\text { smart phone PNS }\end{array}$} & & & 0.906 & 0.872 & 0.659 \\
\hline & TCASP1 & 0.833 & & & \\
\hline & TCASP2 & 0.858 & & & \\
\hline & TCASP3 & 0.772 & & & \\
\hline & TCASP4 & 0.767 & & & \\
\hline & TCASP5 & 0.826 & & & \\
\hline
\end{tabular}

$\mathrm{CR}=$ composite reliability; Ave = average variance extracted.

Table 3. Results of Heterotrait Monotrait Ratio (HTMT) analysis.

\begin{tabular}{cccccc}
\hline HTMT & EPA & $\begin{array}{c}\text { PERCEIVED } \\
\text { RISK }\end{array}$ & $\begin{array}{c}\text { PRIVACY } \\
\text { CONCERN }\end{array}$ & PVSP & TCASP \\
\hline EPA & & & & & \\
PERCEIVED RISK & 0.313 & & & & \\
PRIVACY CONCERN & 0.100 & 0.591 & & & \\
PVSP & 0.767 & 0.198 & 0.068 & & \\
TCASP & 0.339 & 0.436 & 0.210 & 0.474 & \\
\hline
\end{tabular}

has asserted that the statistical significance of the individual paths in a mediation model was not a pre-condition to proclaim whether a mediator mediates the relationship between two variables. The specific indirect effect [29] of PR between 
Table 4. Outer VIF values.

\begin{tabular}{cl}
\hline Outer VIF Values & VIF \\
\hline EPA1 & 1.421 \\
EPA2 & 1.698 \\
EPA3 & 1.617 \\
PC1 & 2.732 \\
PC2 & 3.249 \\
PC3 & 2.722 \\
PC4 & 1.664 \\
PR1 & 1.219 \\
PR2 & 1.301 \\
PR3 & 1.214 \\
PVSP1 & 2.047 \\
PVSP2 & 2.970 \\
PVSP3 & 2.312 \\
PVSP4 & 1.834 \\
PVSP5 & 1.621 \\
TCASP1 & 2.073 \\
TCASP2 & 2.437 \\
TCASP3 & 1.905 \\
TCASP4 & 2.247 \\
TCASP5 & 2.610 \\
\hline & \\
\hline & \\
\hline
\end{tabular}

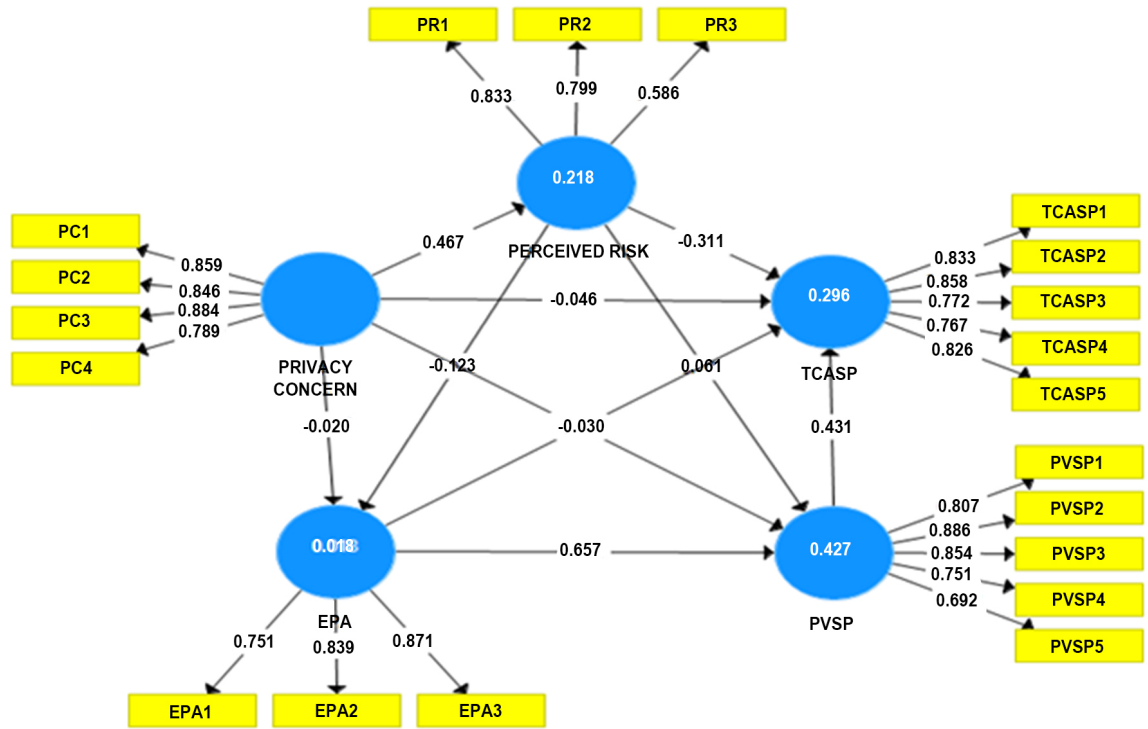

Figure 1. The structural model.

the constructs PC and TCASP was calculated and found to be significant (Table 6). The R square values (Table 5) of the construct PVSP was 0.42 and of TCASP was 0.29 which was contextually adequate. 
Table 5. R square and $\mathrm{r}$ square adjusted.

\begin{tabular}{ccc}
\hline R Square & R Square & R Square Adjusted \\
\hline EPA & 0.018 & 0.006 \\
PERCEIVED RISK & 0.218 & 0.213 \\
PVSP & 0.427 & 0.416 \\
TCASP & 0.296 & 0.279 \\
\hline
\end{tabular}

As shown in Table 6, following are the observations:

- EPA has a significant direct effect on PVSP $\left(\beta=0.657^{* * * *}, \mathrm{t}=12.390\right)$ which supports Hypothesis 1.

- $\mathrm{PR}$ has a significant direct negative effect on TCASP $\left(\beta=-0.311^{\star * * *}, \mathrm{t}=\right.$ 3.698) which supports Hypothesis 2.

- Counter intuitively, PC does not have a significant negative direct effect on EPA $(\beta=-0.020 \mathrm{n} . \mathrm{s}, \mathrm{t}=0.159)$, which does not support Hypothesis 3 .

- PC has a positive significant direct effect on PR $\left(\beta=0.467^{\star * * *}, t=6.414\right)$, which supports Hypothesis 4.

- Hypothesis 5 was also supported which stated that PVSP has a positive significant direct effect on TCASP $(\beta=0.431, \mathrm{t}=6.366)$.

- Finally, it was also observed that PR mediates the relationship between PC and TCASP since the specific indirect effect was significant $\left(\beta=-0.145^{\star * *}, \mathrm{t}\right.$ $=2.931$ ) which supports hypothesis 6 .

The degree of predictive relevance was measured by calculating the $Q$ square values which were found to be greater than 0 (Table 7) and thus it was ascertained that the model had predictive relevance.

\subsection{Test for Goodness of Fit}

The goodness of fit measure was ascertained as per Henseler and Sarstedt [42]. The standardized root mean square residual (SRMR) was 0.083 which was well below the threshold limit of 0.14 . Thus, the model was an overall good fit (Table 8).

\subsection{Multi Group Analysis (MGA)}

Another perspective of the behavioral economics theory which underpins this study was to ascertain the gender based difference in the MAs use of mobile technologies for the purpose of professional networking. As per Morris et al. [43] the difference between the behavior of the gender was worth ascertaining. As per the "Parametric test" (Table 9) there was no significant "gender related difference" among the MAs in their usage of mobile technologies for professional networking. Thus gender does not have any influence on the use of mobile technologies for professional networking.

\subsection{Importance Performance Analysis (IPMA)}

The construct "PVSP" was found to be the most impactful construct (total effect $=0.431)$ (Table 10) followed by construct perceived risk (total effect $=-0.335)$. 
Table 6. Significant individual path coefficients in the structural model.

\begin{tabular}{|c|c|c|c|}
\hline Structural Path & $\begin{array}{l}\text { Path Coefficient } \\
\qquad(\mathrm{t} \text { value })\end{array}$ & $\mathrm{p}$ values & Conclusion \\
\hline EPA -> PVSP & $\begin{array}{c}0.657 \\
(12.390)\end{array}$ & 0.000 & $\mathrm{H} 1$ is supported. \\
\hline PERCEIVED RISK -> TCASP & $\begin{array}{l}-0.311 \\
(3.698)\end{array}$ & 0.000 & $\mathrm{H} 2$ is supported. \\
\hline PRIVACY CONCERN -> EPA & $\begin{array}{l}-0.020 \\
(0.159)\end{array}$ & 0.873 & $\mathrm{H} 3$ is not supported. \\
\hline $\begin{array}{c}\text { PRIVACY CONCERN -> } \\
\text { PERCEIVED RISK }\end{array}$ & $\begin{array}{c}0.467 \\
(6.414)\end{array}$ & 0.000 & H4 is supported. \\
\hline PVSP -> TCASP & $\begin{array}{c}0.431 \\
(6.366)\end{array}$ & 0.000 & H5 is supported. \\
\hline $\begin{array}{l}\text { PRIVACY CONCERN -> } \\
\text { PERCEIVED RISK -> TCASP }\end{array}$ & $\begin{array}{l}-0.145 \\
(2.931)\end{array}$ & 0.004 & $\begin{array}{l}\text { H6 is supported. } \\
\text { Perceived risk mediates the } \\
\text { relationship between Privacy } \\
\text { Concern and TCASP. }\end{array}$ \\
\hline \multicolumn{4}{|c|}{$\begin{array}{l}\text { n.s. not-significant; }{ }^{*}|\mathrm{t}| \geq 1.65 \text { at } \mathrm{p}=0.10 \text { level; }{ }^{* *}|\mathrm{t}| \geq 1.96 \text { at } \mathrm{p}=0.05 \text { level; } * * *|\mathrm{t}| \geq 2.58 \text { at } \mathrm{p}=0.01 \text { level; } \\
{ }_{* * * *}|\mathrm{t}| \geq 3.29 \text { at } \mathrm{p}=0.001 \text { level. }\end{array}$} \\
\hline $\begin{array}{c}\text { Construct cross validated commu } \\
\text { BLINDFOLDING }\end{array}$ & ality: & SSF & $\mathrm{Q}^{2}(=1-\mathrm{SSE} / \mathrm{SSO})$ \\
\hline EPA & 504.000 & 331.3 & 0.343 \\
\hline PERCEIVED RISK & 504.000 & 409.2 & 0.188 \\
\hline PRIVACY CONCERN & 672.000 & 348.7 & 0.481 \\
\hline PVSP & 840.000 & 465.9 & 0.445 \\
\hline TCASP & 840.000 & 453.0 & 0.461 \\
\hline
\end{tabular}

Table 8. Standardised root mean square residual.

\begin{tabular}{ccc}
\hline Model Fit Summary & Saturated Model & Estimated Model \\
\hline SRMR & 0.083 & 0.083 \\
\hline
\end{tabular}

However, the performance of the construct PVSP (Table 11) as ascertained by IPMA was 70.705 and the performance of the construct perceived risk (Table 11 ) as ascertained by IPMA was 46.210 . This connotes that there is much more scope to improve upon the perceived risk construct than any other construct to further the use of mobile technologies for professional networking by MAs (Figure 2). Thus, it is recommended that the first priority of firms offering professional networking services through smartphones should be to make the MAs more comfortable by reducing their risk perception of mobile technologies.

Thus the final model was well measured, with a good structural fit for further in-depth analysis. The use of advanced tools such as IPMA and MGA added fresh insights for the study. 
Table 9. Parametric test for multi group analysis on the basis of gender of the MA.

\begin{tabular}{|c|c|c|c|}
\hline & $\begin{array}{c}\text { Path Coefficients-diff } \\
\text { (|GROUP_GENDERMGA (0.0) - } \\
\text { GROUP_GENDERMGA (1.0)|) }\end{array}$ & t-Value & $\mathrm{p}$-Value \\
\hline EPA -> PVSP & 0.104 & 0.783 & 0.435 \\
\hline EPA $->$ TCASP & 0.112 & 0.637 & 0.525 \\
\hline PERCEIVED RISK -> EPA & 0.459 & 1.382 & 0.169 \\
\hline PERCEIVED RISK -> PVSP & 0.132 & 0.766 & 0.445 \\
\hline PERCEIVED RISK -> TCASP & 0.091 & 0.448 & 0.655 \\
\hline PRIVACY CONCERN -> EPA & 0.013 & 0.050 & 0.960 \\
\hline $\begin{array}{l}\text { PRIVACY CONCERN -> } \\
\text { PERCEIVED RISK }\end{array}$ & 0.243 & 1.360 & 0.176 \\
\hline PRIVACY CONCERN -> PVSP & 0.181 & 1.018 & 0.310 \\
\hline PRIVACY CONCERN -> TCASP & 0.231 & 1.305 & 0.194 \\
\hline PVSP -> TCASP & 0.134 & 0.840 & 0.402 \\
\hline
\end{tabular}

Table 10. Construct total effects for [TCASP] IPMA.

\begin{tabular}{cc}
\hline & TCASP \\
\hline EPA & 0.253 \\
PERCEIVED RISK & -0.335 \\
PRIVACY CONCERN & -0.197 \\
PVSP & 0.431 \\
\hline
\end{tabular}

Table 11. Construct performances for [TCASP] IPMA.

\begin{tabular}{cc}
\hline & Performances \\
\hline EPA & 71.825 \\
PERCEIVED RISK & 46.210 \\
PRIVACY CONCERN & 63.598 \\
PVSP & 70.705 \\
\hline
\end{tabular}

\section{Discussion}

The prospect theory in the context of the behavioral economics theory posits that individuals desire to avoid loss rather than to make profit which explain the focus on perceived risk and the privacy concerns of MAs. Scholars such as Adam Smith discussed key concepts such as loss aversion, over confidence and self-control [44] which are contextually very relevant for mobile technologies. By adding the behavioral factors, the explanatory power of the economic models is improved [44] and this study was an attempt in this direction.

The study found that the influence of EPA and PVSP (in terms of path coefficients and statistical significance) was much stronger than the influence of PC 


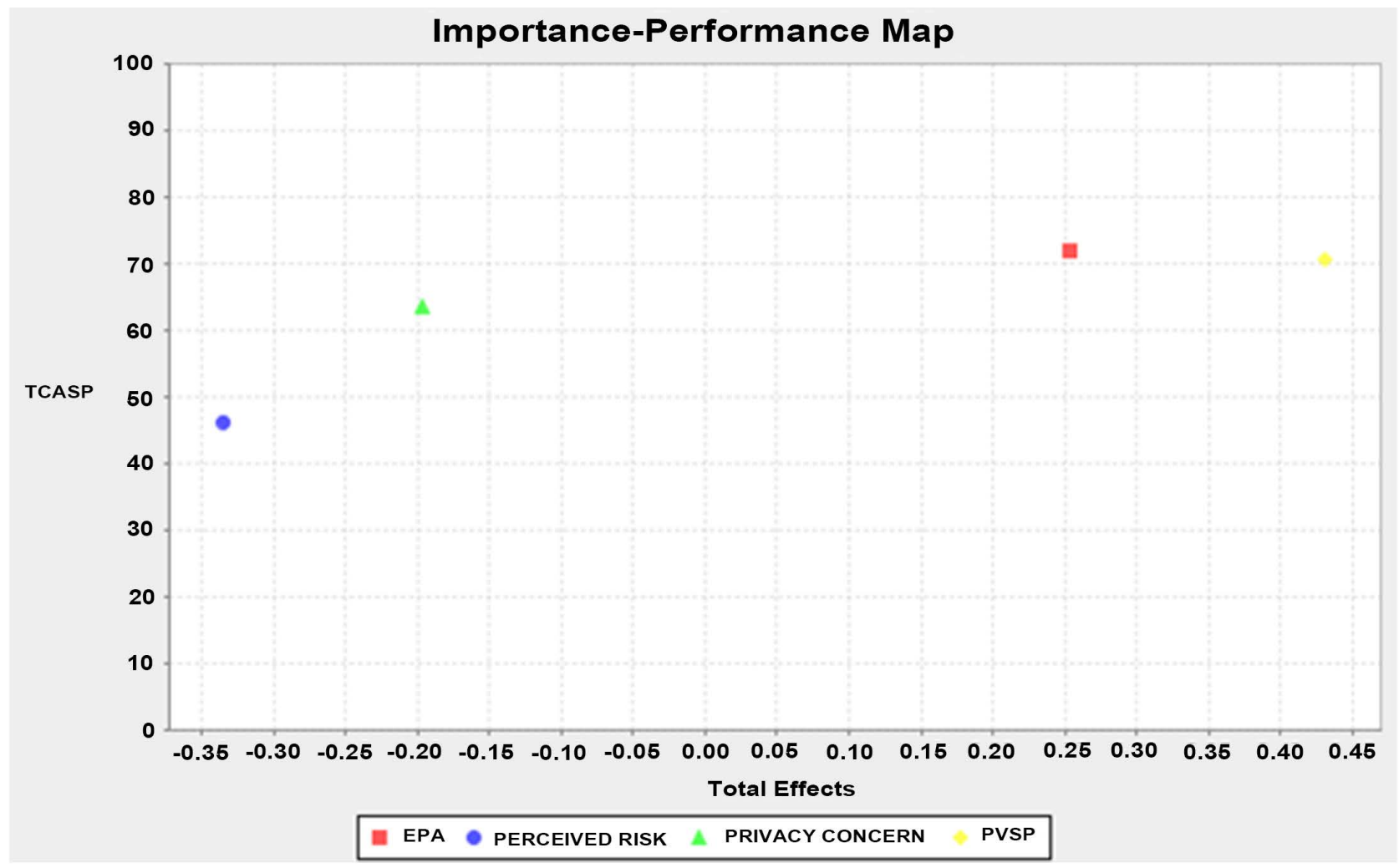

Figure 2. IPMA graph.

and PR. This finding lends support to Lankton and McKnight [22] people continue to use social media despite the perceived potential risks as the positive influences outrun the negative influences.

The study found out that the enjoyment of professional networking activity (EPA) has a direct significant effect on the perceived value of smartphone professional networking service (PVSP). This can be attributed to the fact that the ease of using a smartphone leads to a satisfying and enjoyable end user experience which eventually leads to higher utility creation.

As expected, the perceived risk (PR) had a significant negative effect on the trust in advice acquired from a smartphone professional networking service (TCASP). The risk perception, as also found out by IPMA results, was by far the highest priority for improvement in order to ensure that MAs use smartphone for professional networking. Counter intuitively, privacy concern (PC) did not have a significant direct effect on the enjoyment of professional networking activity. This could be explained by the user friendly interface and other useful features which make professional networking a pleasurable experience for MAs. However, privacy concerns (PC) did have a significant direct effect on the perceived risks $(\mathrm{PR})$ which is surprising, given the fact that there are regular reassurances which the professional networking websites offer to the MAs and other professionals that their data is safe and will not be shared with others. The 2017-2018 episodes of data breach was perhaps one of the key reasons for the perceived risks. The PVSP had a direct positive effect on TCASP. Finally, it was 
observed that PR mediates the relationship between PC and TCASP. The specific indirect effect was negative and significant.

Overall this study contributes by bringing new empirical insights on the actual usage of mobile technology for professional networking purposes in an emerging market context.

\section{Conclusion}

This study, by using a behavioral economics lens, found out that the enjoyment of professional networking activity (EPA) has a direct significant effect on the perceived value of smartphone professional networking service (PVSP) and that the perceived risk (PR) had a significant negative effect on the trust in advice acquired from a smartphone professional networking service (TCASP). Privacy concerns (PC) had a significant direct effect on the perceived risks (PR). The PVSP had a direct positive effect on TCASP. It was observed that PR mediates the relationship between PC and TCASP and that the gender of the MA had no impact on the use of professional networking services.

\section{Conflicts of Interest}

The authors declare no conflicts of interest regarding the publication of this paper.

\section{References}

[1] Guzavicius, A., Gižienė, V. and Žalgiryte, L. (2015) Education as Public Good: Behavioral Economics Approach. Procedia-Social and Behavioral Sciences, 191, 884-889. https://doi.org/10.1016/j.sbspro.2015.04.401

[2] Garcia, M.J.R. (2013) Financial Education and Behavioral Finance: New Insights into the Role of Information in Financial Decisions. Journal of Economic Surveys, 27, 297-315. https://doi.org/10.1111/j.1467-6419.2011.00705.x

[3] Ponce, L.B., Méndez, J.A.J. and Peñalvo, F.J.G. (2014) November. A Systematic Review of Using Mobile Devices in Medical Education. 2014 International Symposium on Computers in Education (SIIE), 205-210. https://doi.org/10.1109/SIIE.2014.7017731

[4] Boruff, J.T. and Storie, D. (2014) Mobile Devices in Medicine: A Survey of How Medical Students, Residents, and Faculty Use Smartphones and Other Mobile Devices to Find Information. Journal of the Medical Library Association, JMLA, 102, 22. https://doi.org/10.3163/1536-5050.102.1.006

[5] Chang, S.E., Shen, W.C. and Liu, A.Y. (2016) Why Mobile Users Trust Smartphone Social Networking Services? A PLS-SEM Approach. Journal of Business Research, 69, 4890-4895. https://doi.org/10.1016/j.jbusres.2016.04.048

[6] Costa-Montenegro, E., Barragáns-Martínez, A.B. and Rey-López, M. (2012) Which App? A Recommender System of Applications in Markets: Implementation of the Service for Monitoring Users' Interaction. Expert Systems with Applications, 39, 9367-9375. https://doi.org/10.1016/j.eswa.2012.02.131

[7] Okazaki, S., Navarro-Bailón, M.Á. and Molina-Castillo, F.J. (2012) Privacy Concerns in Quick Response Code Mobile Promotion: The Role of Social Anxiety and 
Situational Involvement. International Journal of Electronic Commerce, 16, 91-120. https://doi.org/10.2753/JEC1086-4415160404

[8] Pitt, L.F., Parent, M., Junglas, I., Chan, A. and Spyropoulou, S. (2011) Integrating the Smartphone into a Sound Environmental Information Systems Strategy: Principles, Practices and a Research Agenda. The Journal of Strategic Information Systems, 20, 27-37. https://doi.org/10.1016/j.jsis.2010.09.005

[9] Foss, N.J., Lyngsie, J. and Zahra, S.A. (2013) The Role of External Knowledge Sources and Organizational Design in the Process of Opportunity Exploitation. Strategic Management Journal, 34, 1453-1471. https://doi.org/10.1002/smj.2135

[10] Nebus, J. (2006) Building Collegial Information Networks: A Theory of Advice Network Generation. Academy of Management Review, 31, 615-637. https://doi.org/10.5465/amr.2006.21318921

[11] Venkatesh, V., Thong, J.Y. and Xu, X. (2012) Consumer Acceptance and Use of Information Technology: Extending the Unified Theory of Acceptance and Use of Technology. MIS Quarterly, 157-178.

[12] Chen, X.P. and Chen, C.C. (2004) On the Intricacies of the Chinese Guanxi: A Process Model of Guanxi Development. Asia Pacific Journal of Management, 21, 305-324. https://doi.org/10.1023/B:APJM.0000036465.19102.d5

[13] Casciaro, T., Gino, F. and Kouchaki, M. (2016) Learn to Love Networking. Harvard Business Review, 94, 104-107.

[14] Varma, A., Bhalotia, K. and Gambhir, K. (2018) Innovating for Competitive Advantage: Managerial Risk-Taking Ability Counterbalances Management Controls. Journal of Management and Governance, 1-21. https://doi.org/10.1007/s10997-018-9422-Z

[15] Gunawan, D.D. and Huarng, K.H. (2015) Viral Effects of Social Network and Media on Consumers' Purchase Intention. Journal of Business Research, 68, 2237-2241. https://doi.org/10.1016/j.jbusres.2015.06.004

[16] Grandison, T. and Sloman, M. (2000) A Survey of Trust in Internet Applications. IEEE Communications Surveys \& Tutorials, 3, 2-16. https://doi.org/10.1109/COMST.2000.5340804

[17] Kane, G.C., Fichman, R.G., Gallaugher, J. and Glaser, J. (2009) Community Relations 2.0. Harvard Business Review, 87, 45-50.

[18] Cheng, Y.H. and Ho, H.Y. (2015) Social Influence's Impact on Reader Perceptions of Online Reviews. Journal of Business Research, 68, 883-887. https://doi.org/10.1016/j.jbusres.2014.11.046

[19] Teas, R.K. and Agarwal, S. (2000) The Effects of Extrinsic Product Cues on Consumers' Perceptions of Quality, Sacrifice, and Value. Journal of the Academy of marketing Science, 28, 278-290. https://doi.org/10.1177/0092070300282008

[20] Sheth, J.N., Newman, B.I. and Gross, B.L. (1991) Why We Buy What We Buy: A Theory of Consumption Values. Journal of Business Research, 22, 159-170. https://doi.org/10.1016/0148-2963(91)90050-8

[21] Nofer, M., Hinz, O., Muntermann, J. and Roßnagel, H. (2014) The Economic Impact of Privacy Violations and Security Breaches. Business \& Information Systems Engineering, 6, 339-348. https://doi.org/10.1007/s12599-014-0351-3

[22] Lankton, N.K. and McKnight, D.H. (2011) What Does It Mean to Trust Facebook? Examining Technology and Interpersonal Trust Beliefs. ACM SIGMIS Database: The Database for Advances in Information Systems, 42, 32-54.

[23] Dowling, G.R. and Staelin, R. (1994) A Model of Perceived Risk and Intended 
Risk-Handling Activity. Journal of Consumer Research, 21, 119-134. https://doi.org/10.1086/209386

[24] Chin, W.W. (1998) The Partial Least Squares Approach to Structural Equation Modeling. Modern Methods for Business Research, 295, 295-336.

[25] DeVellis, R.F. (2016) Scale Development: Theory and Applications. Vol. 26, Sage, Thousand Oaks.

[26] Podsakoff, P.M., MacKenzie, S.B., Lee, J.Y. and Podsakoff, N.P. (2003) Common Method Biases in Behavioral Research: A Critical Review of the Literature and Recommended Remedies. Journal of Applied Psychology, 88, 879. https://doi.org/10.1037/0021-9010.88.5.879

[27] Tenenhaus, M., Vinzi, V.E., Chatelin, Y.M. and Lauro, C. (2005) PLS Path Modeling. Computational Statistics \& Data Analysis, 48, 159-205. https://doi.org/10.1016/j.csda.2004.03.005

[28] Lowry, P.B. and Gaskin, J. (2014) Partial Least Squares (PLS) Structural Equation Modeling (SEM) for Building and Testing Behavioral Causal Theory: When to Choose It and How to Use It. IEEE Transactions on Professional Communication, 57, 123-146. https://doi.org/10.1109/TPC.2014.2312452

[29] Ringle, C.M., Wende, S. and Becker, J.M. (2015) SmartPLS 3. SmartPLS GmbH, Boenningstedt. http://www.smartpls.com

[30] Shin, D.H. (2010) The Effects of Trust, Security and Privacy in Social Networking: A Security-Based Approach to Understand the Pattern of Adoption. Interacting with Computers, 22, 428-438. https://doi.org/10.1016/j.intcom.2010.05.001

[31] Tan, X., Qin, L., Kim, Y. and Hsu, J. (2012) Impact of Privacy Concern in Social Networking Web Sites. Internet Research, 22, 211-233. https://doi.org/10.1108/10662241211214575

[32] McKnight, D.H., Choudhury, V. and Kacmar, C. (2002) Developing and Validating Trust Measures for e-Commerce: An Integrative Typology. Information Systems Research, 13, 334-359. https://doi.org/10.1287/isre.13.3.334.81

[33] Moon, J.W. and Kim, Y.G. (2001) Extending the TAM for a World-Wide-Web Context. Information \& Management, 38, 217-230. https://doi.org/10.1016/S0378-7206(00)00061-6

[34] Zeithaml, V.A. (1988) Consumer Perceptions of Price, Quality, and Value: A Means-End Model and Synthesis of Evidence. The Journal of Marketing, 52, 2-22. https://doi.org/10.2307/1251446

[35] Hsu, M.H., Chang, C.M. and Yen, C.H. (2011) Exploring the Antecedents of Trust in Virtual Communities. Behaviour \& Information Technology, 30, 587-601. https://doi.org/10.1080/0144929X.2010.549513

[36] Gefen, D. (2000) E-Commerce: The Role of Familiarity and Trust. Omega, 28, 725-737. https://doi.org/10.1016/S0305-0483(00)00021-9

[37] Ali, M. and Park, K. (2016) The Mediating Role of an Innovative Culture in the Relationship between Absorptive Capacity and Technical and Non-Technical Innovation. Journal of Business Research, 69, 1669-1675. https://doi.org/10.1016/j.jbusres.2015.10.036

[38] Nunnally, J. (1978) Psychometric Methods. McGraw-Hill Book Co., New York.

[39] Henseler, J., Ringle, C.M. and Sarstedt, M. (2015) A New Criterion for Assessing Discriminant Validity in Variance-Based Structural Equation Modeling. Journal of the Academy of Marketing Science, 43, 115-135. https://doi.org/10.1007/s11747-014-0403-8 
[40] Preacher, K.J. and Hayes, A.F. (2008) Asymptotic and Resampling Strategies for Assessing and Comparing Indirect Effects in Multiple Mediator Models. Behavior Research Methods, 40, 879-891. https://doi.org/10.3758/BRM.40.3.879

[41] Field, A. (2009) Discovering Statistics Using SPSS. 3rd Edition, Sage Publication, London.

[42] Henseler, J. and Sarstedt, M. (2013) Goodness-of-Fit Indices for Partial Least Squares Path Modeling. Computational Statistics, 28, 565-580.

https://doi.org/10.1007/s00180-012-0317-1

[43] Morris, M.G., Venkatesh, V. and Ackerman, P.L. (2005) Gender and Age Differences in Employee Decisions about New Technology: An Extension to the Theory of Planned Behavior. IEEE Transactions on Engineering Management, 52, 69-84. https://doi.org/10.1109/TEM.2004.839967

[44] Thaler, R.H. (2016) Behavioral Economics: Past, Present, and Future. American Economic Review, 106, 1577-1600. https://doi.org/10.1257/aer.106.7.1577 